\title{
Update on Lynch syndrome genomics
}

\author{
Päivi Peltomäki ${ }^{1}$
}

Published online: 12 February 2016

(c) The Author(s) 2016. This article is published with open access at Springerlink.com

\begin{abstract}
Four main DNA mismatch repair (MMR) genes have been identified, MLH1, MSH2, MSH6, and PMS2, which when mutated cause susceptibility to Lynch syndrome (LS). LS is one of the most prevalent hereditary cancer syndromes in man and accounts for $1-3 \%$ of unselected colorectal carcinomas and some $15 \%$ of those with microsatellite instability and/or absent MMR protein. The International Society for Gastrointestinal Hereditary Tumours (InSiGHT) maintains a database for LS-associated mutations since 1996. The database was recently reorganized to efficiently gather published and unpublished data and to classify the variants according to a five-tiered scheme linked to clinical recommendations. This review provides an update of germline mutations causing susceptibility to LS based on information available in the InSiGHT database and the latest literature. MMR gene mutation profiles, correlations between genotype and phenotype, and possible mechanisms leading to the characteristic spectrum of tumors in LS are discussed in light of the different functions of MMR proteins, many of which directly serve cancer avoidance.
\end{abstract}

Keywords Lynch syndrome - Mutation - Epimutation · Tumor spectrum $\cdot$ DNA mismatch repair

Päivi Peltomäki

Paivi.Peltomaki@Helsinki.Fi

1 Department of Medical and Clinical Genetics, University of Helsinki, P. O. Box 63, Haartmaninkatu 8, 00014 Helsinki, Finland

\section{DNA mismatch repair genes: shared and specialized functions}

Functional DNA mismatch repair (MMR) is vital for basic biology and cancer avoidance. The main function of MMR proteins is to maintain genomic stability by correcting single-base mismatches and insertion/deletion loops (IDL) that may arise during replication [1]. Malfunction of MMR results in a mutator phenotype and microsatellite instability (MSI) characteristic of most tumors from Lynch syndrome (LS) and some $15 \%$ of sporadic tumors [2]. MMR proteins also recognize diverse types of endogenous and exogenous damage, such as that induced by oxidation [3] or alkylation [4], and correct the lesions, or if this is not possible, signal DNA damage to cell cycle arrest or apoptosis. MMR proteins regulate genetic recombination by correcting mismatches that may occur in recombination during meiosis and by suppressing recombination between homeologous (=related but non-identical) sequences during mitosis [5]. Unexpectedly, the MMR system can also promote mutations when needed. For example, the MMR proteins MSH4 and MSH5 facilitate meiotic crossover between homologous chromosomes [6]. Additionally, MMR proteins promote somatic hypermutation and class switch of antibody genes [7].

In humans, five MutS homologues (MSH2, MSH6, MSH3, MSH4, and MSH5) and four MutL homologues (MLH1, PMS2, PMS1, and MLH3) have been identified which can form heterodimers in different combinations [810] (Fig. 1). The main mismatch-binding factor in humans is hMutS $\alpha$, consisting of MSH2 and MSH6, which recognizes single-base mispairs and IDLs. Another mismatchbinding heterodimer is hMutS $\beta$, formed by MSH2 and MSH3, which mainly acts on IDLs. Upon mismatch binding, the hMutS complex undergoes an ATP-driven 
Fig. 1 The different hMutS and hMutL complexes in human MMR. In addition to MMR proteins, the repair process requires a number of other proteins, such as proliferating cell nuclear antigen (PCNA), replication factor $\mathrm{C}$ (RFC), EXO1 (a $5^{\prime}-3^{\prime}$ exonuclease), DNA helicases, RPA (replication protein A, a singlestranded DNA binding protein), DNA polymerases, and DNA ligase

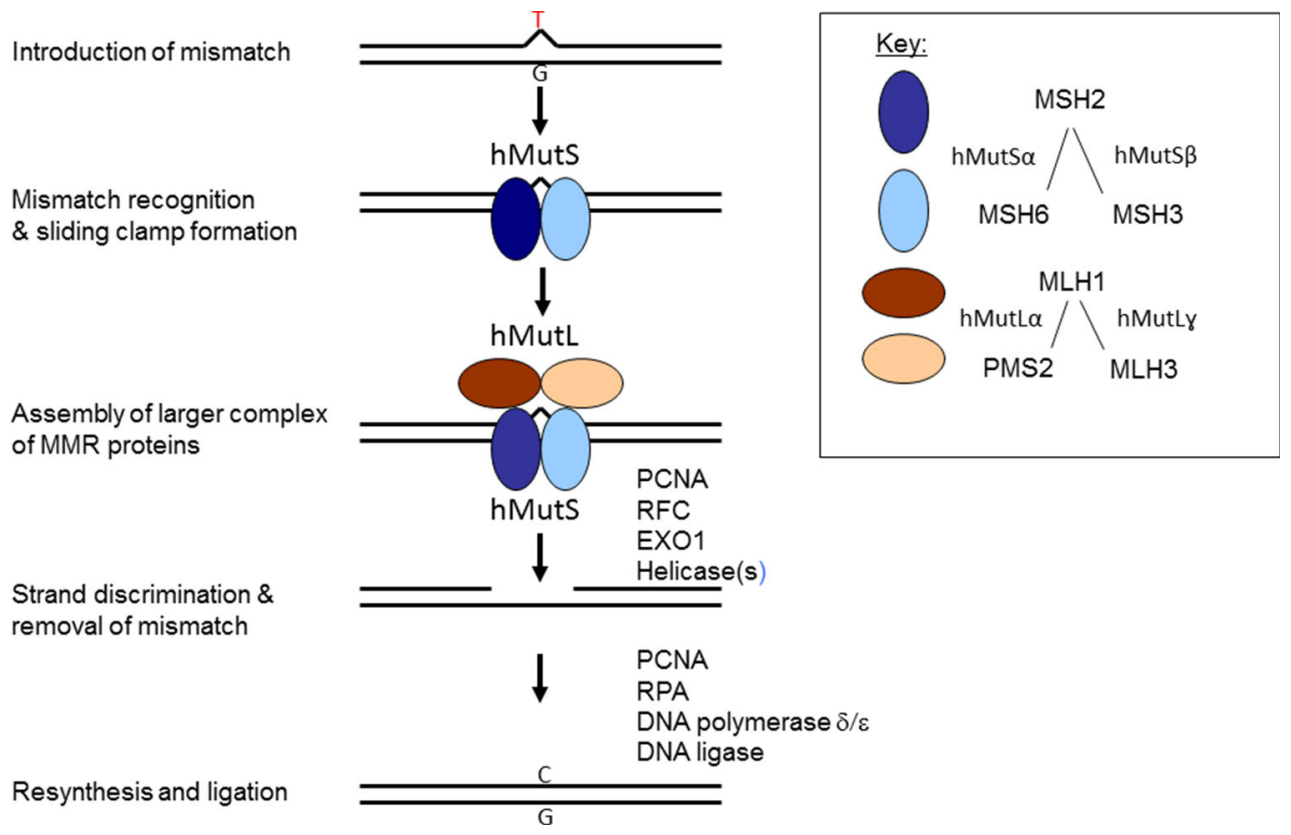

conformational change into a sliding clamp and a hMutL heterodimer is recruited. The main hMutL complex is hMutL $\alpha$, consisting of MLH1 and PMS2 and participating in the repair of single-base mismatches and IDLs. Alternative hMutL heterodimers are hMutL $\gamma$, composed of MLH1 and MLH3, which may predominantly contribute to IDL repair, and hMutL $\beta$ (MLH1 and PMS1), which does not seem to participate in MMR. When the hMutS-hMutL complex encounters a strand discontinuity, an excision machinery is recruited, the mismatch containing fragment is degraded, and a new strand synthesized [7, 9].

Substrate specificities of the individual MMR proteins are reflected in the different MSI phenotypes observed in tumors from LS patients. $M S H 2$ and $M L H 1$ mutations are associated with high-degree instability involving mononucleotide and dinucleotide (and other short tandem) repeats [11]. The same is true for PMS2 mutations [12]. MSH6 mutations are associated with low-degree MSI with a preferential involvement of mononucleotide repeats [13]. In tumors from $\mathrm{MLH} 3$ mutation carriers, mononucleotide repeats may be less informative than dinucleotide and tetranucleotide repeats [14] and phenotypes ranging from MSI-high [14] to no MSI [15] have been reported.

\section{Germline mutations in MMR genes predisposing to $\mathbf{L S}$}

\section{Shares of individual MMR genes}

MLH1, MSH2, MSH6 and PMS2 account for 40, 34, 18, and $8 \%$, respectively, of the 3000 unique germline sequence variants of MMR genes deposited to the International Society for Gastrointestinal Hereditary Tumours (InSiGHT) database ([16] and www.insight-group.org, date accessed December 19th, 2015). The different substrate specificities described above may explain why $M L H 1$ and MSH2 are the most important predisposing genes for LS (their protein products are obligatory components in all types of heterodimers, Fig. 1), followed by MSH6 and PMS2, whereas $M L H 3$ mutations are rare (functionally redundant with $P M S 2$ ), and no LS-predisposing germline mutations are known for $M S H 3$ (functionally redundant with MSH6). No LS-associated germline mutations have been detected in MSH4 or MSH5 (their primary role is in meiotic recombination rather than MMR).

\section{Mutation spectra}

Mutations are scattered throughout the MMR genes (www. insight-group.org). Figure 2 displays the gene-specific distributions of germline variants by the type of mutation and predicted coding change [17]. Most $M L H 1, M S H 2$, and MSH6 mutations are truncating (predominantly nonsense or frameshift mutations). Moreover, the share of missense changes, which lead to single amino acid substitutions, is significant ( $\sim 30-60 \%)$ for all four genes. The abundance of missense mutations prompted the InSiGHT to undertake a large-scale effort to classify MMR gene variants according to pathogenicity, based on variant and family characteristics on the one hand and results from various functional assays on the other hand [16]. A five-tiered classification of the International Agency for Research on Cancer was adopted since it is linked to clinical 
Fig. 2 Distributions of the types of germline variants across each MMR gene. The analysis is based on data deposited in the InSiGHT database [17] and is restricted to variants with coding changes. The total numbers of variants per gene included in the analysis are 1104 for $M L H 1,883$ for MSH2, 414 for MSH6, and 197 for $P M S 2$
MLH1

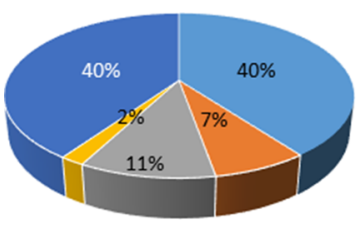

MSH6

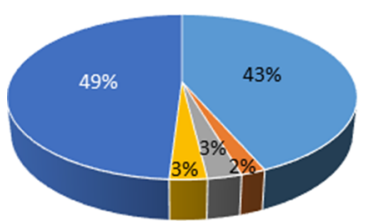

MSH2

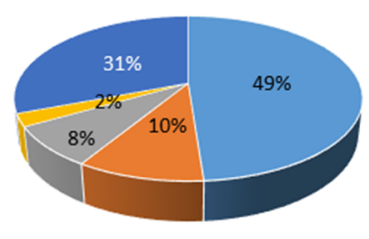

PMS2

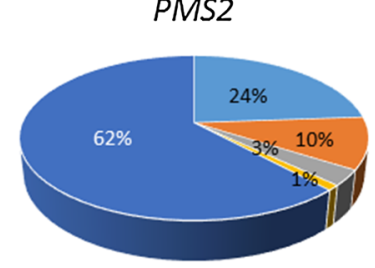

Nonsense or frameshift

Splice

Missense

Large rearrangement

In-frame

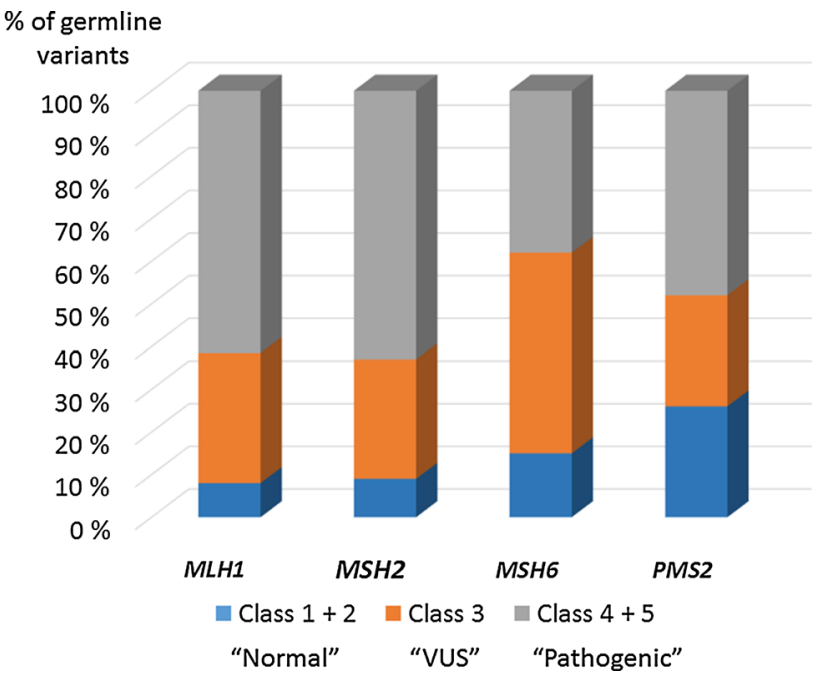

Fig. 3 Distributions of the different pathogenicity classes within the LS-associated MMR genes. The relative shares of normal variants (pathogenicity classes 1 and 2), VUSes (class 3), and pathogenic mutations (classes 4 and 5) reported for each MMR gene in the InSiGHT database [16] are depicted. The analysis includes 932 sequence variants for $M L H 1,842$ for $M S H 2,449$ for $M S H 6$, and 137 for PMS2

specific sequence characteristics. For example, c. $942+3 \mathrm{~A}>\mathrm{T}$, a splicing mutation in intron 5 of $\mathrm{MSH} 2$ and one of the most frequently recurring MMR gene mutations worldwide, is likely to arise as a consequence of misalignment while replicating 26 consecutive adenines, of which the mutation-associated adenine is the first [20]. The same $\mathrm{A}_{26}$ repeat is part of BAT26, a key marker in MSI detection [21]. The c. $942+3 \mathrm{~A}>\mathrm{T}$ mutation arises de novo in some populations [20] and represents a founder mutation in other populations [22]. Founder mutations originate from a single ancestor and become enriched in isolated populations [23]. Based on the extent of haplotype conservation, the age of founder mutations in MMR genes ranges from a few hundred to more than a thousand years or alternatively, represent founder mutations [19]. Certain regions of MMR genes may be mutation-prone due to 
[19]. To date, over 50 proven founder mutations in MMR genes are known from all over the world and may account for over $50 \%$ of all LS families in some populations [19].

\section{Rates of mutation detection in LS families}

Germline mutations in MMR genes are detectable in up to $88 \%$ of LS families fulfilling the Amsterdam criteria [24, 25] and showing MSI in tumors [26, 27]. Smaller or atypical families and families not pre-screened for MMR deficiency in tumor tissues may display mutation frequencies of 10-40\% depending on the criteria of ascertainment $[26,28,29]$. A genetic point mutation is the predominant type of germline mutation in MMR genes in most populations [26, 27, 30]. Analysis of LS cohorts from several different geographic locations yielded a frequency of $15 \%$ (68 unrelated kindreds out of 439) for large genomic rearrangements; among 48 different rearrangements, 29 affected MSH2, 13 MLH1, 2 MSH6 and 4 PMS2 [31]. A few percent of Lynch-suspected families with MMR-deficient tumors and negative for point mutations and large rearrangements are due to constitutional epimutations in MMR genes (see below).

Over half of MMR-deficient tumors that are not explained by germline mutations or (acquired or constitutional) promoter methylation of MMR genes ("Lynch-like syndrome") were recently shown to arise as a consequence of somatic mutations in MMR genes [32-34] occasionally combined with POLE/POLD1 defects [35], i.e. are nonhereditary as a rule. MMR gene mutations are very rare in families with MMR-proficient tumors, even if they meet the Amsterdam criteria (Familial Colorectal Cancer Type X) [36]. The genetic basis of Familial Colorectal Cancer Type $\mathrm{X}$ families seems heterogeneous and predisposing genes and mutations remain unknown in a majority [37-39].

\section{Constitutional epimutations in LS predisposition}

Constitutional epimutation refers to hypermethylation at the promoter of one allele of a given gene leading to silencing of expression from that allele in all main somatic tissues. Constitutional epimutation of $\mathrm{MLHl}$ occurs in 2-3\% of mutation-negative Lynch-suspected families with silenced MLH1 expression in tumors [40-42]. Since constitutional epimutations are reversible during meiosis [43], epimutations segregate in a non-Mendelian fashion and are seldom associated with strong family histories of cancer. Epimutations secondary to genetic mutations constitute an exception and may arise on ancestral founding haplotypes [44]. The prevalence of $M L H I$ constitutional epimutations in colorectal cancers lacking MLH1 expression and showing $M L H 1$ methylation in tumor tissue was reported to be $0 \%$ among unselected cases and $16 \%$ among cases fulfilling the revised Bethesda criteria [21], suggesting that testing for $M L H 1$ epimutations should regularly be restricted to the latter group of patients [45].

Constitutional epimutations of $M S H 2$ are secondary to deletions of the $3^{\prime}$ end of the EPCAM gene which make transcription of EPCAM read into the adjacent, structurally normal $M S H 2$ gene inducing its promoter to be methylated [46]. EPCAM deletion-associated $M S H 2$ epimutations vary a lot in frequency between populations depending on possible founder effects and may account for 10-40\% of families with absent MSH2 protein in tumors [42, 46]. Such epimutations show regular Mendelian transmission along with EPCAM deletion in pedigrees [46].

\section{Genotype-phenotype correlations}

\section{Cancer risks associated with germline mutations in individual MMR genes}

The lifetime risks of cancer are significantly higher in $M S H 2$ and $M L H 1$ mutation carriers compared to carriers of MSH6 or PMS2 mutations, which may reflect functional redundancy of MSH6 (with MSH3) and PMS2 (with MLH3 and PMS1) (see above). The lifetime risk by age 70 of any LS-associated cancer has been found to range between $57 \%$ [47] and close to $80 \%$ [48] for $\mathrm{MSH} 2$ and $59 \%$ [47] and 65\% [48] for MLH1. For MSH6, lifetime risks of $25 \%$ for males and females combined [47] and $24 \%$ (males) and $40 \%$ (females) [49] have been reported. Heterozygous PMS2 mutation carriers may have a 25-32 \% lifetime risk of any cancer [50].

Among the various cancers arising in $\mathrm{MSH} 2$ and $\mathrm{MLHI}$ mutation carriers, the highest lifetime risk is for colorectal cancer, followed by endometrial cancer and other extracolonic cancers; moreover, $\mathrm{MSH} 2$ mutations may be associated with higher risks of extracolonic cancers compared to $M L H 1$ mutations [48, 51]. Female carriers of MSH6 mutations are at a higher risk of endometrial than colorectal cancer $[47,49,52]$. The same may be true for heterozygous carriers of $P M S 2$ mutations [50]. Furthermore, MSH6 and PMS2 mutations show reduced agespecific penetrance, resulting in higher average ages at onset of various cancers in MSH6 [52] and PMS2 [50, 53] carriers compared to $M S H 2$ or $M L H 1$ mutation carriers, although family- and/or mutation-specific variations exist. No clear-cut correlations have been observed between the type (e.g., truncating vs. missense) or location (e.g., relative to different functional domains) of a MMR gene mutation and clinical phenotype. 


\section{LS tumor spectrum}

A major puzzle in LS (in common with a majority of familial cancer syndromes) is the specific spectrum of tumors in constitutional mutation carriers. The Amsterdam II criteria [25] acknowledge cancers of the colon and rectum, endometrium, small bowel, ureter, and renal pelvis as LS-associated cancers, based on their significant overrepresentation in LS compared to the average population. Since these criteria were formulated, significantly increased standardized incidence ratios have repeatedly been reported for several other cancers as well, including cancers of the stomach, ovaries, and pancreas [54, 55]. Combined with molecular profiles characteristic of LS (e.g., consistent MMR protein loss or MSI [56-58], inclusion of these tumors in the LS spectrum seems justified. For breast cancer, the observed standardized incidence ratios vary from comparable to the average population [59, 60] to significantly elevated [54, 55], making it difficult to conclude whether or not breast cancer belongs to the LS spectrum. A recent comparative study on proven mutation carriers versus non-carriers did find a significant difference in the rate of MMR deficient breast carcinomas between those two groups (65 vs. $0 \%, P<0.001$ ) [61]. Moreover, the age at onset in mutation carriers depended on the MMR status of their tumors (earlier onset if the tumor was MMRdeficient), suggesting a role for deficient MMR in breast cancer development in LS [61].

\section{Factors that may contribute to the LS tumor spectrum}

As described above, the individual MMR genes may be associated with somewhat different tumor spectra. In addition, a number of other factors may contribute to the LS tumor spectrum. Tissue-specific patterns of MMR

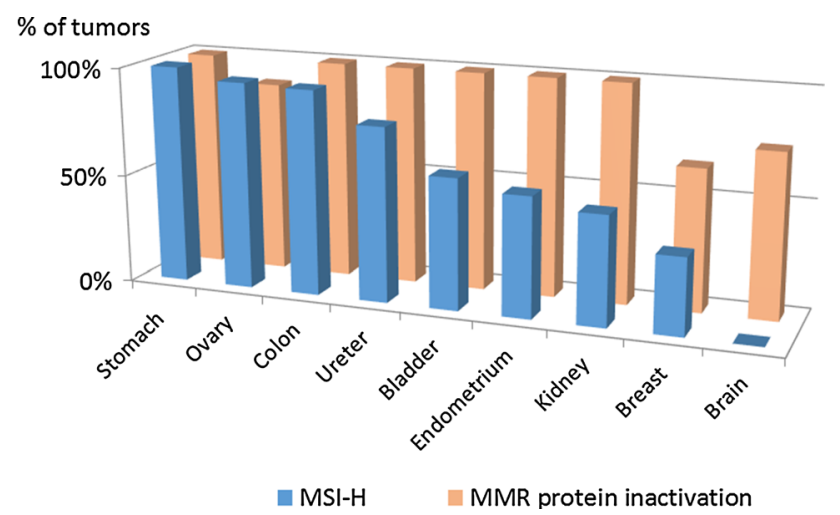

Fig. 4 Tumor-specific patterns of MMR defects. Percentages of tumors with MSI-high and MMR protein inactivation among cancers arising in different organs in germline carriers of MMR gene mutations from a nation-wide registry $[57,61,62]$ are shown deficiency in cancers from MMR gene mutation carriers (Fig. 4) may constitute one such factor. While immunohistochemical analysis of malignant tumors regularly demonstrates the absence of MMR protein corresponding to the gene mutant in the germline, the frequencies of tumors with MSI-high vary, being $80 \%$ or above for stomach, ovary, colon, and ureter cancer, $\sim 50 \%$ for bladder, endometrium, and kidney cancer, and $35 \%$ or below for breast and brain tumors [57, 61, 62]. Clonal heterogeneity is a feature of LS and sporadic MMR-deficient tumors $[63,64]$ and may in part explain the different frequencies of MSI between tumor types. Moreover, BAT markers show shorter allelic shifts in endometrial cancers compared to colorectal cancers from LS patients [65]. Such differences may be important considering the fact that genes with repetitive sequences in coding regions are mutation-prone in MMR-deficient cancers. Different genes confer selective advantage in different cancers, for example, the $T G F \beta$ superfamily is a mutational target in gastrointestinal cancers and PTEN in endometrial cancers [65, 66]. Tissue-specificity for MMR deficiency and genes targeted by failing MMR may therefore contribute to organselectivity.

Two lines of evidence imply that the dosage of the MMR gene or protein is important for phenotype. First, homozygosity or compound heterozygosity for germline mutation gives rise to a distinct syndrome, constitutional mismatch repair deficiency syndrome (CMMRD). Currently, 146 patients from 91 families with this syndrome are known [67]. Childhood cancers of the hematological system and brain, signs of neurofibromatosis type 1 (caféau-lait spots) and Turcot syndrome (coexistence of colorectal tumor and brain tumor) are common manifestations of CMMRD. The peculiar tumor spectrum may reflect the sensitivity of particular (e.g. neural and hematological) progenitor cells to MMR deficiency via specific somatic target genes (NF1 mutation [68]). PMS2 and MSH6 predominate over $M S H 2$ and $M L H 1$ as genes underlying CMMRD [67]. Contrary to traditional LS with heterozygous MMR gene mutations, CMMRD patients lack expression of the MMR protein(s) in question not only in cancer tissue but in normal tissue as well. MSI in tumor tissues varies in the same way as in conventional LS (present in gastrointestinal tumors but absent in brain tumors as shown for LS in Fig. 4). Standard techniques cannot usually detect MSI in peripheral blood lymphocytes because of clonal heterogeneity, whereas immortalized lymphoblastoid cells may reveal a MSI phenotype [67].

Another line of evidence in support of the importance of MMR gene or protein dosage comes from observations that the presence of the wild-type copy of a MMR gene in somatic cells is not always sufficient for a normal function (haploinsufficiency). While MMR genes usually comply 
with Knudson's two-hit hypothesis for tumor suppressor genes [69] as evidenced by the lack of the responsible MMR protein in LS-associated cancers (biallelic inactivation), colorectal adenoma development seems possible in LS even if the wild-type allele of the predisposing MMR gene is retained $[70,71]$. Other possible molecular "hits", such as epigenetic inactivation of tumor suppressor genes [71] may contribute to tumor initiation in such haploinsufficient cells. Haploinsufficiency may be functionspecific; for example, it has been demonstrated that DNA damage signaling requires a higher dosage of MMR protein than the repair function [72]. Failure of apoptosis signaling likely provides MMR-deficient cells with selective advantage needed for tumorigenesis [73]. Different organs may have different requirements for MMR gene dosage [61, 74], which may influence their susceptibility to tumor development.

As discussed above, the MMR system recognizes several other types of DNA damage besides replication errors, including oxidative [3] and alkylating [4] damage, as well as heterocyclic amine (e.g., PhIP) DNA adducts [75]. Such damage can be exogenous (e.g., PhIP is a cooked meatderived mutagen [75]) or endogenous (e.g., oxidation resulting from normal cellular metabolism or inflammation [76]). Organs commonly exposed to such damage, such as the gastrointestinal tract and endometrial epithelium, would obviously be at elevated risk of cancer development, especially in individuals with deficient MMR. Unhealthy diet ("snack" pattern [77] and tobacco smoking [78] have been shown to increase colorectal adenoma risk in MMR gene mutation carriers, which might imply a reduced capacity to correct dietary and tobacco-associated damage.

Tumor development initiated by replication errors or carcinogen-induced mutations may proceed at different rates in different tissues depending on their proliferative activity [79]. Colon and many other epithelial cells have fast turnovers, and there may be less time to repair replication errors if cell cycles are short [80]. Furthermore, in colon and other epithelial organs, stem cell divisions continue throughout life. Hematopoietic tissue, too, is highly proliferative, but may be less prone to malignancies because of fewer stem cell divisions during lifetime [80]. These general concepts are in agreement with the fact that a majority of LS-associated tumors are epithelial and that MMR deficiency also predisposes to hematological malignancies, but mainly in the context of CMMRD only.

Frameshift mutations typical of MMR deficiency result in the formation of neoantigens recognized by the immune system. Consequently, colon, gynecological, and other tumors from LS patients display high levels of tumor infiltrating lymphocytes (TILs) [81, 82]. The abundance of $\mathrm{CD} 8+$ cells (dominant in TILs) is a good prognostic sign in LS and sporadic cancers [81, 83]. On the other hand, frameshift mutations may also affect cell surface proteins responsible for antigen processing and presentation and thereby facilitate escape from immune surveillance [84]. Varying frequencies of MMR defects in different types of tumors (Fig. 4), combined with possible variations in the inherent efficacy of immune surveillance in different organs, may thus contribute to organ-specific tumor susceptibility in LS.

\section{Concluding remarks}

Research on LS conducted to date has greatly advanced our understanding of the significance of the MMR system in human cancer. Yet, many essential questions wait for definitive answers regarding the mechanisms of tumorigenesis (e.g., two-hit inactivation vs. haploinsufficiency) and the complex relationship between genotype and phenotype (e.g., genetic vs. non-genetic influences; unequivocal definition of the LS tumor spectrum) to mention a few. Targeted gene panels based on next-generation sequencing $[85,86]$ will be changing the approach to screen for predisposing mutations in LS and other hereditary disorders in the coming years. The simultaneous screening of all LSassociated MMR genes and other possible susceptibility genes in LS-suspected cases is likely to more accurately define the spectrum of genes and mutations predisposing to LS and the population incidence of LS. Next-generation sequencing of the whole exomes and genomes is also anticipated to provide new insights into the genetic basis of colon cancer families that are unrelated to MMR defects (Familial Colorectal Cancer Type X) [38, 87, 88].

Comprehensive genetic, epigenetic, and expressional cataloguing of tumor alterations in analogy to ongoing efforts on sporadic cancers (e.g., by the Cancer Genome Atlas Network [89, 90]) will be useful to define the developmental mechanisms of colonic and extracolonic tumors in LS and to better understand the molecular basis of organ-specific tumor susceptibility. Targeted studies [57, 91] have already revealed distinct mutational patterns in LS tumors that may explain the disease outcome and be clinically actionable. When linked to clinical parameters, comprehensive molecular profiles of constitutional and tumor tissues will be informative to establish clinical correlations of molecular aberrations and facilitate the management of individuals with LS.

Acknowledgments This review is based on my presentation given at the Dr. Henry T. Lynch Symposium (September 17-18, 2015). The public domain of the InSiGHT database is acknowledged as a main source of mutation data presented and discussed. This work was supported by the Academy of Finland (Grant No. 257795), The Finnish Cancer Organizations, the Sigrid Juselius Foundation, the Nordic Cancer Union, the Faculty of Medicine at the University of 
Helsinki, Biocentrum Helsinki, and Jane and Aatos Erkko Foundation.

Open Access This article is distributed under the terms of the Creative Commons Attribution 4.0 International License (http://crea tivecommons.org/licenses/by/4.0/), which permits unrestricted use, distribution, and reproduction in any medium, provided you give appropriate credit to the original author(s) and the source, provide a link to the Creative Commons license, and indicate if changes were made.

\section{References}

1. Modrich P (2006) Mechanisms in eukaryotic mismatch repair. J Biol Chem 281:30305-30309

2. Peltomäki P (2003) Role of DNA mismatch repair defects in the pathogenesis of human cancer. J Clin Oncol 21:1174-1179

3. Bridge G, Rashid S, Martin SA (2014) DNA mismatch repair and oxidative DNA damage: implications for cancer biology and treatment. Cancers 6:1597-1614

4. Stojic L, Brun R, Jiricny J (2004) Mismatch repair and DNA damage signalling. DNA Repair 3:1091-1101

5. Surtees JA, Argueso JL, Alani E (2004) Mismatch repair proteins: key regulators of genetic recombination. Cytogenet Genome Res 107:146-159

6. Clark N, Wu X, Her C (2013) MutS Homologues hMSH4 and hMSH5: genetic variations, functions, and implications in human diseases. Curr Genomics 14:81-90

7. Bak ST, Sakellariou D, Pena-Diaz J (2014) The dual nature of mismatch repair as antitumor and mutator: for better or for worse. Front Genet 5:287

8. Peltomäki P (2005) Lynch syndrome genes. Fam Cancer 4:227-232

9. Li G-M (2008) Mechanisms and functions of DNA mismatch repair. Cell Res 18:85-98

10. Jiricny J (2013) Postreplicative mismatch repair. Cold Spring Harb Perspect Biol 5:a012633

11. Sanchez de Abajo A, de la Hoya M, van Puijenbroek M et al (2006) Dual role of LOH at MMR loci in hereditary non-polyposis colorectal cancer? Oncogene 25:2124-2130

12. Hendriks YMC, Jagmohan-Changur S, van der Klift HM et al (2006) Heterozygous mutations in PMS2 cause hereditary nonpolyposis colorectal carcinoma. Gastroenterology 130:312-322

13. WuY Berends MJW, Mensink RGJ et al (1999) Association of hereditary nonpolyposis colorectal cancer-related tumors displaying low microsatellite instability with MSH6 germline mutations. Am J Hum Genet 65:1291-1298

14. Wu Y, Berends MJW, Sijmons RH et al (2001) A role for MLH3 in hereditary nonpolyposis colorectal cancer. Nat Genet 29:137-138

15. Liu H-X, Zhou X-L, Liu T et al (2003) The role of hMLH3 in familial colorectal cancer. Cancer Res 63:1894-1899

16. Thompson BA, Spurdle AB, Plazzer J-P et al (2014) Application of a five-tiered scheme for standardized classification of 2,360 unique mismatch repair gene variants lodged on the InSiGHT locus-specific database. Nat Genet 46:107-115

17. Plazzer JP, Sijmons RH, Woods MO et al (2013) The InSiGHT database: utilizing 100 years of insights into Lynch syndrome. Fam Cancer 12:175-180

18. Win AK, Jenkins MA, Buchanan DD et al (2011) Determining the frequency of de novo germline mutations in DNA mismatch repair genes. J Med Genet 48:530-534

19. Ponti G, Castellsague E, Ruini C et al (2015) Mismatch repair genes founder mutations and cancer susceptibility in Lynch syndrome. Clin Genet 87:507-516
20. Desai DC, Lockman JC, Chadwick RB et al (2000) Recurrent germline mutation in MSH2 arises frequently de novo. J Med Genet 37:646-652

21. Umar A, Boland CR, Terdiman JP et al (2004) Revised Bethesda guidelines for hereditary non-polyposis colorectal cancer (Lynch syndrome) and microsatellite instability. J Natl Cancer Inst 96:261-268

22. Froggatt NJ, Green J, Brassett C et al (1999) A common MSH2 mutation in English and North American HNPCC families: origin, phenotypic expression, and sex specific differences in colorectal cancer. J Med Genet 36:97-102

23. Moisio A-L, Sistonen P, Weissenbach J et al (1996) Age and origin of two common MLH1 mutations predisposing to hereditary colon cancer. Am J Hum Genet 59:1243-1251

24. Vasen HF, Mecklin JP, Khan PM, Lynch HT (1991) The international collaborative group on hereditary non-polyposis colorectal cancer (ICG-HNPCC). Dis Colon Rectum 34:424-425

25. Vasen HF, Watson P, Mecklin JP, Lynch HT (1999) New clinical criteria for hereditary nonpolyposis colorectal cancer (HNPCC, Lynch syndrome) proposed by the international collaborative group on HNPCC. Gastroenterology 116:1453-1456

26. Mangold E, Pagenstecher C, Friedl W et al (2005) Spectrum and frequencies of mutations in MSH2 and MLH1 identified in 1721 German families suspected of hereditary nonpolyposis colorectal cancer. Int J Cancer 116:692-702

27. Lagerstedt Robinson K, Liu T et al (2007) Lynch syndrome (hereditary nonpolyposis colorectal cancer) diagnostics in 2006. J Natl Cancer Inst 99:291-299

28. Nyström-Lahti M, Wu Y, Moisio A-L et al (1996) DNA mismatch repair gene mutations in 55 verified or putative kindreds with hereditary non-polyposis colorectal cancer. Hum Mol Genet 5:763-769

29. Wijnen J, Khan PM, Vasen H et al (1997) Hereditary nonpolyposis colorectal cancer families not complying with the Amsterdam criteria show extremely low frequency of mismatch repair gene mutations. Am J Hum Genet 61:329-335

30. Hampel H, Frankel WL, Martin E et al (2005) Screening for the Lynch syndrome (hereditary nonpolyposis colorectal cancer). N Engl J Med 352:1851-1859

31. Van der Klift H, Wijnen J, Wagner A et al (2005) Molecular characterization of the spectrum of genomic deletions in the mismatch repair genes MSH2, MLH1, MSH6, and PMS2 responsible for hereditary nonpolyposis colorectal cancer (HNPCC). Genes Chromosomes Cancer 44:123-138

32. Haraldsdottir S, Hampel H, Tomsic J et al (2014) Colon and endometrial cancers with mismatch repair deficiency can arise from somatic, rather than germline, mutations. Gastroenterology 147:1308-1316

33. Mensenkamp AR, Vogelaar IP, van Zelst-Stams WAG et al (2014) Somatic mutations in MLH1 and MSH2 are a frequent cause of mismatch repair deficiency in Lynch syndrome-like tumors. Gastroenterology 146:643-646

34. Geurts-Giele WRR, Leenen CHM, Dubbink HJ et al (2014) Somatic aberrations of mismatch repair genes as a cause of microsatellite-unstable cancers. J Pathol 234:548-559

35. Jansen AML, van Wezel T, van den Akker BEWM et al (2015) Combined mismatch repair and POLE/POLD1 defects explain unresolved suspected Lynch syndrome cancers. Eur J Hum Genet (in press)

36. Lindor NM, Rabe K, Petersen GM et al (2005) Lower cancer incidence in Amsterdam-I criteria families without mismatch repair deficiency: familial colorectal cancer type X. JAMA 293:1979-1985

37. Nieminen TT, Abdel-Rahman WM, Ristimäki A et al (2011) BMPR1A mutations in hereditary nonpolyposis colorectal cancer without mismatch repair deficiency. Gastroenterology 141:e23-e26 
38. Nieminen TT, O’Donohue M-F, Wu Y (2014) Germline mutation of RPS20, encoding a ribosomal protein, predisposes to hereditary nonpolyposis colorectal carcinoma without DNA mismatch repair deficiency. Gastroenterology 147:595-598

39. Dominguez-Valentin M, Therkildsen C, Da Silva S, Nilbert M (2015) Familial colorectal cancer type X: genetic profiles and phenotypic features. Mod Pathol 28:30-36

40. Gylling A, Ridanpää M, Vierimaa $O$ et al (2009) Large genomic rearrangements and germline epimutations in Lynch syndrome. Int J Cancer 124:2333-2340

41. Ward RL, Dobbins T, Lindor NM et al (2013) Identification of constitutional MLH1 epimutations and promoter variants in colorectal cancer patients from the Colon Cancer Family Registry. Genet Med 15:25-35

42. Niessen RC, Hofstra RMW, Westers H et al (2009) Germline hypermethylation of MLH1 and EPCAM deletions are a frequent cause of Lynch syndrome. Genes Chromosomes Cancer 48:737-744

43. Hitchins MP, Wong JJ, Suthers G et al (2007) Inheritance of a cancer-associated MLH1 germ-line epimutation. N Engl J Med 356:697-705

44. Kwok CT, Vogelaar IP, van Zelst-Stams WA et al (2014) The MLH1 c.-27C $>$ A and c. $85 \mathrm{G}>\mathrm{T}$ variants are linked to dominantly inherited MLH1 epimutation and are borne on a European ancestral haplotype. Eur J Hum Genet 22:617-624

45. Castillejo A, Hernandez-Illan E, Rodriguez-Soler M et al (2015) Prevalence of constitutional epimutations as a cause of Lynch syndrome in unselected versus selected consecutive series of patients with colorectal cancer. J Med Genet 52:498-502

46. Ligtenberg MJ, Kuiper RP, Chan TL et al (2009) Heritable somatic methylation and inactivation of $\mathrm{MSH} 2$ in families with Lynch syndrome due to deletion of the $3^{\prime}$ exons of TACSTD1. Nat Genet 41:112-117

47. Bonadona V, Bonaiti B, Olschwang S et al (2011) Cancer risks associated with germline mutations in MLH1, MSH2, and MSH6 genes in Lynch syndrome. JAMA 305:2304-2310

48. Vasen HFA, Stormorken A, Menko FH et al (2001) MSH2 mutation carriers are at higher risk of cancer than MLH1 mutation carriers: a study of hereditary nonpolyposis colorectal cancer families. J Clin Oncol 19:4074-4080

49. Baglietto L, Lindor NM, Dowty JG et al (2010) Risks of Lynch syndrome cancers for MSH6 mutation carriers. J Natl Cancer Inst 102:193-201

50. Senter L, Clendenning M, Sotamaa K et al (2008) The clinical phenotype of Lynch syndrome due to germ-line PMS2 mutations. Gastroenterology 135:419-428

51. Bandipalliam B, Garber J, Syngal S, Kolodner RD (2004) Clinical presentation correlates with the type of mismatch repair gene involved in hereditary nonpolyposis colon cancer. Gastroenterology 126:936-937

52. Hendriks YMC, Wagner A, Morreau H et al (2004) Cancer risk in hereditary nonpolyposis colorectal cancer due to MSH6 mutations: impact on counselling and surveillance. Gastroenterology 127:17-25

53. Ten Broeke SW, Brohet RM, Tops CM et al (2014) Lynch syndrome caused by germline PMS2 mutations: delineating the cancer risk. J Clin Oncol 33:319-325

54. Engel C, Loeffler M, Steinke V et al (2012) Risks of less common cancers in proven mutation carriers with Lynch syndrome. J Clin Oncol 30:4409-4415

55. Win AK, Young JP, Lindor NM et al (2012) Colorectal and other cancer risks for carriers and noncarriers from families with a DNA mismatch repair gene mutation: a prospective cohort study. J Clin Oncol 30:958-964

56. Gylling A, Abdel-Rahman WM, Juhola M et al (2007) Is gastric cancer part of the tumor spectrum of hereditary nonpolyposis colorectal cancer? A molecular genetic study. Gut 56:926-933
57. Niskakoski A, Kaur S, Renkonen-Sinisalo L et al (2013) Distinct molecular profiles in Lynch syndrome-associated and sporadic ovarian carcinomas. Int J Cancer 133:2596-2608

58. Karamurzin Y, Zeng Z, Stadler ZK et al (2012) Unusual DNA mismatch repair-deficient tumors in Lynch syndrome: a report of new cases and review of the literature. Hum Pathol 43:1677-1687

59. Aarnio M, Sankila R, Pukkala E et al (1999) Cancer risk in mutation carriers of DNA mismatch repair genes. Int $\mathrm{J}$ Cancer $81: 214-218$

60. Watson P, Vasen HF, Mecklin J-P et al (2008) The risk of extracolonic, extra-endometrial cancer in the Lynch syndrome. Int $\mathrm{J}$ Cancer 123:444-449

61. Lotsari JE, Gylling A, Abdel-Rahman WM et al (2012) Breast carcinoma and Lynch syndrome-molecular analysis of tumors arising in mutation carriers, non-carriers, and sporadic cases. Breast Cancer Res 14:R90

62. Gylling A, Nieminen TT, Abdel-Rahman WM (2008) Differential cancer predisposition in Lynch syndrome: insights from molecular analysis of brain and urinary tract tumors. Carcinogenesis 29:1351-1359

63. Giuffre G, Müller A, Brodegger T et al (2005) Microsatellite analysis of hereditary nonpolyposis colorectal cancer-associated colorectal adenomas by laser-assisted microdissection: correlation with mismatch repair protein expression provides new insights in early steps of tumorigenesis. J Mol Diagn 7:160-170

64. Beggs AD, Domingo E, Abulafi M (2013) A study of genomic instability in early preneoplastic colonic lesions. Oncogene 32:5333-5337

65. Kuismanen SA, Moisio A-L, Schweizer P (2002) Endometrial and colorectal tumors from patients with hereditary nonpolyposis colon cancer display different patterns of microsatellite instability. Am J Pathol 160:1953-1958

66. Woerner SM, Benner A, Sutter C et al (2003) Pathogenesis of DNA repair-deficient cancers: a statistical meta-analysis of putative Real Common Target genes. Oncogene 22:22262235

67. Bodo S, Colas C, Buhard O et al (2015) Diagnosis of constitutional mismatch repair-deficiency syndrome based on microsatellite instability and lymphocyte tolerance to methylating agents. Gastroenterology 149:1017-1029

68. Wang Q, Montmain G, Ruano E et al (2003) Neurofibromatosis type 1 gene as a mutational target in a mismatch repair-deficient cell type. Hum Genet 112:117-123

69. Knudson AG Jr (1971) Mutation and cancer: statistical study of retinoblastoma. Proc Natl Acad Sci USA 68:820-823

70. Yurgelun MB, Goel A, Homick JL et al (2012) Microsatellite instability and DNA mismatch repair protein deficiency in Lynch syndrome colorectal polyps. Cancer Prev Res 5:574-582

71. Valo S, Kaur S, Ristimäki A et al (2015) DNA hypermethylation appears early and shows increased frequency with dysplasia in Lynch syndrome-associated colorectal adenomas and carcinomas. Clin Epigenetics 7:71

72. Cejka P, Stojic L, Mojas N et al (2003) Methylation-induced $\mathrm{G}(2) / \mathrm{M}$ arrest requires a full complement of the mismatch repair protein hMLH1. EMBO J 22:2245-2254

73. Kawate H, Itoh R, Sakumi K et al (2000) A defect in a single allele of the Mlh1 gene causes dissociation of the killing and tumorigenic actions of an alkylating carcinogen in methyltransferase-deficient mice. Carcinogenesis 21:301-305

74. Ollikainen M, Hannelius U, Lindgren CM (2007) Mechanisms of inactivation of MLH1 in hereditary nonpolyposis colorectal carcinoma: a novel approach. Oncogene 26:4541-4549

75. Smith-Roe SL, Löhr CV, Bildfell RJ et al (2006) Induction of aberrant crypt foci in DNA mismatch repair-deficient mice by the food-borne carcinogen 2-amino-1-methyl-6-phenyl-imidazo [4,5b] pyridine (PhIP). Cancer Lett 244:79-85 
76. Derry MM, Raina K, Agarwal C et al (2013) Identifying molecular targets of lifestyle modifications in colon cancer prevention. Front Oncol 3:119

77. Botma A, Vasen HFA, van Duijnhoven FJB et al (2013) Dietary patterns and colorectal adenomas in Lynch syndrome. Cancer 119:512-521

78. Winkels RM, Botma A, van Duijnhoven FJB et al (2012) Smoking increases the risk of colorectal adenomas in patients with Lynch syndrome. Gastroenterology 142:241-247

79. Tomasetti C, Vogelstein B (2015) Cancer etiology. Variation in cancer risk among tissues can be explained by the number of stem cell divisions. Science 347:78-81

80. Albanes D, Winick M (1988) Are cell number and cell proliferation risk factors for cancer? J Natl Cancer Inst 80:772-775

81. Drescher KM, Sharma P, Lynch HT (2010) Current hypotheses on how microsatellite instability leads to enhanced survival of Lynch syndrome patients. Clin Dev Immunol 2010:170432

82. Shia J, Black D, Hummer AJ et al (2008) Routinely assessed morphological features correlate with microsatellite instability status in endometrial cancer. Hum Pathol 39:116-125

83. Fridman WH, Pages F, Sautes-Fridman C, Galon J (2012) The immune contexture in human tumors: impact on clinical outcome. Nat Rev Cancer 12:298-306
84. Kloor M, von Knebel Doeberitz M (2010) Immune evasion of microsatellite unstable colorectal cancers. Int J Cancer 127:1001-1010

85. Pritchard CC, Smith C, Salipante SJ et al (2012) ColoSeq provides comprehensive Lynch and polyposis syndrome mutational analysis using massively parallel sequencing. J Mol Diagn 14:357-366

86. Yurgelun MB, Allen B, Kaldate RR et al (2015) Identification of a variety of mutations in cancer predisposition genes in patients with suspected Lynch syndrome. Gastroenterology 149:604-613

87. Schulz E, Klampfl P, Holzapfel S et al (2014) Germline variants in the SEMA4A gene predispose to familial colorectal cancer type X. Nat Commun 5:5191

88. Segui N, Mina LB, Lazaro C et al (2015) Germline mutations in FAN1 cause hereditary colorectal cancer by impairing DNA repair. Gastroenterology 149:563-566

89. The Cancer Genome Atlas Network (2012) Comprehensive molecular characterization of human colon and rectal cancer. Nature 487:330-337

90. The Cancer Genome Atlas Network (2013) Integrated genomic characterization of endometrial carcinoma. Nature 497:67-73

91. Kloth M, Ruesseler V, Engel C et al (2015) Activating ERBB2/ HER2 mutations indicate susceptibility to pan-HER inhibitors in Lynch and Lynch-like colorectal cancer. Gut (in press) 